\title{
Iris Murdoch e Clarice Lispector: A tradução do romance a cabeça decepada
}

Iris Murdoch and Clarice Lispector: An análisis of the translated novel a cabeça decepada (a severed head)

\author{
Mônica Stefani \\ Universidade Federal de Santa Maria - UFSM - Rio Grande do Sul - Brasil \\ Tiago Ferreira Pereira
}

Universidade Federal de Santa Maria - UFSM - Rio Grande do Sul - Brasil

\begin{abstract}
Resumo: As traduções fomentam um diálogo importante e necessário entre leitores de diferentes grupos linguísticos e culturais e cabe ao pesquisador refletir sobre o fazer tradutório de modo a elucidar seus mecanismos e efeitos. Assim, este artigo apresenta uma análise contrastiva de trechos selecionados do romance A Severed Head (1961), da autora anglo-irlandesa Iris Murdoch, e de A Cabeça Decepada, tradução atribuída a Clarice Lispector (conforme nome na capa), publicada pela editora Artenova em 1973. Murdoch e Lispector celebraram seus centenários de nascimento em 2019 e 2020 , respectivamente. Nesta pesquisa, para avaliar como o texto de Murdoch chegou ao público leitor brasileiro, justapomos os excertos e observamos aspectos linguísticos, culturais e intertextuais, tendo Berman (1998), Coracini (2017) e Genette (2009; 2010) como referencial teórico. Este exercício é duplamente esclarecedor: se junta aos demais estudos que abordam Clarice Lispector (como tradutora ou não), e introduz Iris Murdoch no campo dos Estudos Literários (e também de tradução) no Brasil.
\end{abstract}

Palavras-chave: Tradução. Iris Murdoch. Clarice Lispector.

Abstract: Translations foster an important and necessary dialogue between readers of different linguistic and cultural groups and, as such, it is the researcher's task to think about her/his craft so as to elucidate its mechanisms and effects. Thus, this paper presents a contrastive analysis of selected excerpts from A Severed Head (written in 1961 by the Anglo-Irish author Iris Murdoch) and from A Cabeça Decepada, whose translation is said to be by the Brazilian writer Clarice Lispector (as seen on the cover of the book), published by Artenova in 1973. Murdoch and Lispector celebrated their centenaries of birth in 2019 and 2020, respectively. In this research, to assess how Murdoch's text reached the Brazilian reading audience, we juxtaposed the excerpts and paid attention to linguistic, cultural and intertextual aspects, having Berman (1998), Coracini $(2017)$ and Genette $(2009 ; 2010)$ as the theoretical framework. This exercise is doubly clarifying: it joins the other studies that address Clarice Lispector (as a translator or not) while introducing Iris Murdoch in literary (and also in translation) studies in Brazil.

Keywords: Translation. Iris Murdoch. Clarice Lispector. 


\section{Iris Murdoch, Clarice Lispector e a tradução}

Iris Murdoch, uma das vozes da literatura inglesa do século XX, nasceu na Irlanda em 1919, tendo celebrado seu centenário em 2019i, e, assim como outros autores irlandeses, sua fortuna literária foi reconhecida primeiro no lado do Mar da Irlanda, mais precisamente, na Inglaterra. Com formação em Filosofia, Murdoch teve destaque também na literatura, tendo publicado vinte e seis romances, além de uma variedade de outros textos. Ao lado de autores ingleses, como William Golding (1911-1993), Graham Greene (1904-1991) e Anthony Burgess (1917-1993) todos concorrentes ao Nobel de Literatura -, Murdoch era comumente estudada dentro da literatura do "pósguerra", "[...] tendendo a significar um movimento, "the Angry Young Men", a primeira geração de romances feministas [...]." (ENGLISH, 2006, p. 2, tradução nossa)ii. Logo, não causa surpresa que ambas as áreas, filosofia e literatura, estudem seus escritos, pois ela aproveita para inserir tópicos filosóficos em suas narrativas, sem, no entanto, torná-las maçantes. Por exemplo, em A Severed Head, Iris Murdoch baseia a narrativa em seus pressupostos metafísicos. Anne Rowe, estudiosa da obra de Murdoch, comenta sobre A Severed Head:

\begin{abstract}
[...] um romance que explora o sadomasoquismo, a violência e o incesto, e ao lidar com questões tão sensíveis, apoiase nas imagens, na poética e nos símbolos para representar o sentido [...]. O romance sugere que impulsos Freudianos profundos e inexplicáveis impactam o comportamento humano de forma mais palpável do que as leis sociais, e que uma irracionalidade profunda esconde uma frágil fachada de civilização (ROWE, 2019, p. 16, tradução nossa) ${ }^{\mathrm{iii}}$.
\end{abstract}

Ao longo dos últimos 30 anos, foram realizados alguns trabalhos (dissertações, teses, etc.), tantos em inglês quanto em português, que abordaram a obra de Murdoch escrita originalmente em inglês. Pesquisas que tivessem como objeto de análise os escritos de Iris Murdoch, tanto filosóficos quanto ficcionais, traduzidos para o português, ou mesmo no âmbito dos Estudos de Tradução, não apareceram nas nossas pesquisas.
O processo de tradução é complexo e não diz respeito somente a substituir uma palavra pela outra. É verdade que ambos os agentes, autor e tradutor, estão envolvidos em uma complexa rede de comunicação onde ambos são produtores de sentidos que nascem de experiências pessoais singulares, de aspectos linguístico-culturais distintos dentro de condições históricas diferentes (CORACINI, 2017). E o crítico, ao deparar-se com essas malhas de sentido, estabelecidas entre o texto fonte e traduzido, entende que é preciso refletir sobre o processo de tradução e tornar seus mecanismos e efeitos melhor compreendidos. Partindo dessa problemática, este artigo pretende averiguar algumas questões em relação à obra de Murdoch em língua portuguesa, especificamente no Brasiliv

Enquanto o centenário de Murdoch era celebrado em 2019, em 2020, chegava a vez de celebrar o centenário de Lispector. Reconhecendo a importância de ambas as autoras, este artigo analisa alguns excertos do romance $A$ Severed Head (1961), de Iris Murdoch, e da sua tradução, A Cabeça Decepada (1973), atribuída a Clarice Lispector. Vale destacar, antes de proceder à análise paratextual da tradução, que numerosos escritos ${ }^{\vee}$ destacam a faceta de Clarice Lispector como tradutora, o que, segundo Edgar Nolasco (2007, p. 263): “[...] não só alterou seu processo de criação, como vai influenciar diretamente toda sua última produção". Para ela, "quanto mais se revê o texto, mais se tem que mexer e remexer nos diálogos", e assim, "não parar nunca" era um risco a aceitar (GOMES, 2004, p. 42). Já Murdoch tem uma relação mais conturbada com a tradução, haja vista que sua grande frustração foi ter tido sua tradução de Pierrot mon ami (1947), de Raymond Queneau, rejeitada por inúmeras editoras na Inglaterra (ROWE, 2019).

Quanto à organização do artigo, após revisitarmos brevemente a trajetória das duas autoras, partimos para a análise paratextual da tradução em português brasileiro de $A$ Cabeça Decepada e, em seguida, apresentamos a justaposição de fragmentos selecionados do original e da tradução, observando aspectos linguísticos, culturais e intertextuais. Por fim, 
tecemos algumas considerações finais acerca desta pesquisa.

\section{Análise paratextual de $A$ Cabeça Decepada}

O termo paratexto tem sua origem no grego e significa "ao lado de, perto de" e sua acepção moderna foi consolidada pelo teórico francês Gérard Genette (2009), que enxergava o paratexto como um conjunto de elementos textuais que mediam a relação entre livro, autor, editor e leitor (por exemplo, os títulos, os prefácios, as epígrafes, as capas, etc.).

De todos os romances de Iris Murdoch publicados em português brasileiro até hoje ${ }^{\mathrm{vi}}$, três saíram com o selo da Artenova. Levando em consideração essa relação editorial, preliminarmente à análise paratextual, se faz necessário uma breve contextualização histórica do percurso da Artenova. Criada em 1962, no Rio de Janeiro, a editora tinha como objetivo proporcionar, aos leitores brasileiros, acesso a títulos de autores inéditos em solo nacional ou não tão conhecidos ainda por aqui, tendo em seu catálogo, por exemplo, nomes como Anthony Burgess (1917-1993), Raymond Chandler (1888-1959), Sylvia Plath (1932-1963) e J. R. R. Tolkien (1892-1973). De fato, a partir dessa iniciativa, a editora ganhou destaque a partir de 1969. Contudo, nem só de traduções mantinha-se a Artenova, e por essa razão é importante ressaltar a presença de autores nacionais conceituados em seus quadros, como Rubem Fonseca (1925-2020), Carlos Castelo Branco (1920-1993) e João Ubaldo Ribeiro (1941-2014) - além de Clarice Lispector (1920-1977). Ressalta-se ainda, que, se não fosse pelo trabalho realizado pela Artenova, Iris Murdoch provavelmente não teria sido publicada em português brasileiro.

$\mathrm{Na}$ tese de Rony M. Cardoso Ferreira (2016), há a foto da capa da edição brasileiravii, a única até o presente momento, de A Cabeça Decepada. A capa é um elemento importante que compõe o peritexto e que, segundo Gérard Genette (2009), se trata de um aspecto do livro que é bastante recente que possivelmente remonta ao começo do século XIX. "[...] Uma vez descobertos os recursos da capa, parece que muito depressa começou-se a explorá-la" (GENETTE, 2009, p. 27). A arte mostra um homem com a parte superior do seu corpo (cabeça e tronco) aparecendo, com uma marcação em amarelo (cor geralmente associada à loucura) circundando sua cabeça, como se estivesse sendo enforcado por essa linha. No canto superior direito, há o logo da editora em fonte branca. Abaixo da arte de capa, o nome Iris Murdoch aparece em destaque, com fonte rosa e em caixa baixa embora em tamanho maior -, e logo abaixo, a inscrição: 'Autora de O Unicórnio e A Moça Italiana' em fonte branca e em tamanho menor. Já embaixo, o título do romance, A CABEÇA DECEPADA, em na cor branca, em letras com caixa alta e maiores do que as utilizadas para indicar o nome da autora. E no canto inferior direito, o título do original em inglês em caixa baixa, em letra bastante menor e na cor amarela - $A$ Severed Head. De fato, a exposição dos elementos de capa dialoga com algumas proposições de Genette (2009) acerca dos paratextos:

Mas as inscrições do nome na página de rosto e na capa não têm a mesma função: a primeira é modesta e por assim dizer legal, em geral mais discreta do que a do título; a segunda tem dimensões muito variáveis, conforme a notoriedade do autor e, quando as normas de coleção impedem toda e qualquer variação, uma sobrecapa Ihe dá campo livre, ou uma cinta permite repeti-lo em caracteres mais chamativos e, por vezes, sem o prenome, para mostrar como é famoso. O princípio dessa variação na aparência é simples (GENETTE, 2018, p. 40).

O destaque dado ao nome do autor na capa, ou seja, a forma como aparece em relação aos outros elementos, seria proporcional à popularidade que o mesmo possui dentro de uma dada comunidade de leitores (GENETTE, 2009). O destaque referente ao nome da autoria pode ocorrer em função de dois fatores: 1) Ou esse autor é famoso por motivações extra literárias, no sentido de já ser conhecido antes mesmo de ter publicado qualquer material; 2) ou esse autor integra uma prática promocional que tem 0 objetivo de atribuir uma antecipada glória futura atribuída a seu nome (GENETTE, 2009).

$$
\text { A adoção da expressão "autoria atribuída a }
$$
Clarice Lispector" neste artigo se explica porque, tratando-se de uma produção da década de 1970, e 
em que pese seu nome constar na capa da edição, não temos como precisar, pelo menos neste momento, se Clarice Lispector de fato participou desta publicação como tradutora, ou se ela comercializou a autorização (o que era uma prática muito comum na época) para que seu nome constasse na capa para identificar um trabalho que não era seu, mas de outros profissionais (que, consequentemente, ficaram sem seu reconhecimento), no intuito de garantir uma vendagem maior (seguindo, de certo modo, o que Genette menciona), e permitindo, ao mesmo tempo, que Clarice Lispector se dedicasse a outros projetos. Outros estudiosos, como Ferreira (2013), questionam abertamente a autoria de Clarice Lispector nas traduções. De fato, nas décadas de 1960 e 1970, autores renomados comercializavam seus nomes para legitimar a autoria de textos traduzidos (talvez pela busca por uma vendagem maior no mercado, ou mesmo por necessidades financeiras dos próprios autores), o que parece uma possibilidade neste contexto. Segundo Ferreira, a assinatura de Clarice Lispector teria uma função "legitimadora da qualidade da tradução, devido a sua importância como escritora, além de ter auxiliado financeiramente a intelectual em tempos difíceis" (FERREIRA, 2013, p. 176). Apesar de a dúvida ainda pairar no ar, para os propósitos deste artigo, vamos trabalhar com a hipótese de que Clarice Lispector possa ter lido Iris Murdoch (pelo menos para este projeto de tradução da Artenova).

Após o primeiro contato com esse elemento visual, e seguindo a ordem de leitura da esquerda para a direita, encontram-se ainda as informações bibliográficas da edição em questão:

Do original norte-americano A
SEVERED HEAD
Copyright (C) 1961 by Iris Murdoch
Copyright 1974 da edição em
português Editora $\quad$ Artenova
S.A.
Tradução
Clarice Lispector
Revisão
Naasson Vieira Peixoto
Capa
Salvio Negreiros - Studio Artenova

Essas informações aparecem no verso da primeira página do livro e antecipam um erro grave.
Como já mencionado, Iris Murdoch nasceu na Irlanda e, assim como outros conterrâneos seus, acabou ganhando notoriedade e reconhecimento fora do domínio territorial irlandês, mais especificamente em solo inglês. Logo, considerar A Severed Head como um "original norte-americano" parece se tratar de um lapso. Ou talvez haja a possibilidade de que a tradução tenha se baseado em uma edição norte-americana do livro. O texto que aparece no interior da capa, de autoria do poeta piauiense Álvaro Pacheco (1933-), então editor da Artenova, expressa o seguinte:

Com dezesseis romances publicados, dentre os quais alguns best-sellers em diversos países, Iris Murdoch (um dos maiores nomes da literatura inglesa) se supera em criatividade em "A Cabeça Decepada".

Martin Gibbon considerava-se um homem realizado: confortavelmente instalado em sua profissão, uma esposa devotada, uma amante adorável.

Quando sua esposa o abandona, por um de seus melhores amigos, ele sofre intensa crise emocional e inicia um curioso processo de reeducação. Descobre, então, que a boa aparência e o agradar constituem uma insuportável escravidão. A liberação chega de modo inesperado. Uma nova paixão, carregada de impiedade e da ilógica violência de um pesadelo, é o ponto culminante de sua reeducação. Esta é uma história repleta de curiosidade, extravagância, mistério e fantasticamente divertida. A ironia com que trata seus personagens, aliada à fúria perversa com que desenvolve o enredo, dão ao livro um toque todo especial.

Iris Murdoch nasceu em Dublin, filha de pais anglo-irlandeses. Freqüentou a Escola de Badmington, Bristol. Lecionou os clássicos em Sommerville College, Oxford. Muito jovem ainda, veio para Cambridge, aonde cursou no Newham College, filosofia. Em 1948, voltou para Oxford. Por esta ocasião, toma posição quanto aos problemas que lhe interessam, e aí foi membro do Conselho e Assistente de Filosofia no St. Anne's College. Embora irlandesa, enamora-se da capital britânica, que ela tão bem conhece, e que se torna por diversas vezes palco de seus romances. Durante a guerra foi Primeira Assistente de Reabilitação 
das Nações Unidas, em Londres, Bélgica, Áustria.

Desta autora foram anteriormente lançados: "A Moça Italiana", "O Unicórnio". Álvaro Pacheco EDITOR (MURDOCH, 1974, capa e contracapa).

Ademais, o livro não possui epígrafe, prefácio, posfácio, nota introdutória, nem um espaço específico com dados da autora, justamente pelas informações apresentadas nestes parágrafos, na parte interna da capa e da contracapa, já indicarem se tratar do terceiro livro de Iris Murdoch publicado pela Artenova. Sendo assim, infere-se que o leitor à procura deste livro já tenha lido os outros dois. Todavia, encontram-se informações biográficas da autora na parte final da publicação, sublinhando brevemente sua trajetória. Nos primeiros parágrafos do comentário, há destaque para a quantidade de romances produzidos por Murdoch acrescida da devida identificação: "literatura inglesa". Em seguida, aparece o resumo da história, que condiz com o que será apresentado. Já em relação à contracapa, o seguinte texto aparece, abaixo do título em cor magenta e em caixa alta e em fonte de tamanho grande (em destaque):

Iris Murdoch escreve sem complacências. Ao longo das suas páginas, ela tece e disseca com uma precisão naturalista as paixões e os ódios sem nenhum rebuscamento de estilo.

Comparada a Simone de Beauvoir, é considerada superior aos existencialistas franceses.

Escritora original e completa, ocupa um lugar, ao lado de Arthur Koestler e Graham Greene, entre os maiores da literatura inglesa de nossos dias.

Jornal do Brasil (MURDOCH, 1974, contracapa)

Tentou-se recuperar, sem sucesso, o texto dessa resenha que aparece na contracapa do livro como originária do Jornal do Brasil, que na época contava com Clarice Lispector (GOTLIB, 2009, p. 466). É importante chamar atenção a outro ponto na carreira de Lispector, relativo ao aparecimento de um grande número de traduções assinadas por ela e sua relação com Álvaro Pacheco, descrito por Ferreira (2016) como consequente de seu afastamento do jornal, mais precisamente sobre a tradução de $A$ Severed Head:

A escritora, então, assina seis adaptações/traduções no ano de 1974. Duas delas, que foram encomendadas, outra vez, por Álvaro Pacheco e publicadas pela Artenova, tratam-se das traduções dos romances I Heard the Owl Call my Name (1967), de Margaret Craven, e A Severed Head (1961), de Iris Murdoch, os quais receberam por título, respectivamente, Ouvi a Coruja Chamar o meu Nome e $A$ Cabeça Decepada. A primeira narrativa trata da significação da vida e a segunda de uma espécie de reeducação sentimental vivida pelo protagonista, segundo comentários do editor presentes nos versos das capas dos livros em português. Essas traduções provam o quanto a tradutora manteve relações de trabalho com Pacheco, situação que interferiria, sobremaneira, em seu projeto literário (FERREIRA, 2016, p. 148).

De fato, a presença de Pacheco na vida de Clarice Lispector é significativa, vista também pelo ângulo das inter-relações entre as literaturas brasileira e inglesa. Após essa breve análise paratextual, apresentamos alguns excertos da tradução em português brasileiro.

\section{Análise dos trechos}

A leitura cotejada e atenta entre as duas versões, isto é, o original de Iris Murdoch e a tradução atribuída a Clarice Lispector, durou cerca de 6 meses, tendo sido realizada entre fevereiro e julho de 2020. Como foram muitos os trechos identificados, e para respeitar os critérios de limitação de espaço, selecionamos os excertos que chamaram mais nossa atenção e que demonstram os seguintes aspectos: uso (ou não) de notas de rodapé; problemáticas visualizadas entre os idiomas de trabalho, como o tratamento dado aos nomes próprios; diferenças estilísticas; o tratamento da intertextualidade na tradução; e saltos (isto é, trechos que não foram traduzidos) encontrados no produto final.

A presença (ou não) de notas de rodapé é um dos primeiros elementos que chama a atenção de qualquer tradutor. Conforme a definição de Genette (2009, p. 281): 
Uma nota é um enunciado de tamanho variável (basta uma palavra) relativo a um segmento mais ou menos determinado de um texto, e disposto seja em frente seja como referência a esse segmento.

Há apenas uma nota, no início do livro, para a palavra "tutor" (Quadro 1):

Quadro 1 - Nota de rodapé: tutor

\begin{tabular}{|c|c|}
\hline $\begin{array}{l}\text { - É claro que é horrível } \\
\text { você ser um homem de } \\
\text { negócios - disse Georgia. } \\
\text { - É muito mais inteligente. } \\
\text { Devia ter sido um membro } \\
\text { importante de uma } \\
\text { Universidade. Um tutor } \\
\text { por exemplo. } \\
\text { *Tutor - assistente, } \\
\text { membro dignatário das } \\
\text { universidades inglesas } \\
\text { (MURDOCH, 1974, p. } \\
\text { 10). }\end{array}$ & $\begin{array}{l}\text { 'Of course it's ludicrous your } \\
\text { being a businessman,' said } \\
\text { Georgie. 'You're far too } \\
\text { clever. You ought to have } \\
\text { been a don' (MURDOCH, } \\
\text { 1961, p. 10-11). }\end{array}$ \\
\hline
\end{tabular}

Na nota, a explicação se dá para a palavra em português, sem mencionar o vocábulo que aparece no original, que é "don". O texto da nota reflete a definição encontrada na maioria dos dicionários monolíngues de inglês para essa palavra. $\mathrm{Na}$ verdade, chamamos a atenção para o fato de o próprio texto da tradução explicar de algum modo o significado de "don" em português ("um membro importante de uma Universidade"), e que, por parecer adequada neste contexto, por si só já eliminaria a necessidade de manter o segmento seguinte ("Um tutor, por exemplo"). Neste trecho, talvez possa ter ocorrido algum lapso na parte de revisão - a exemplo do que será visto em outros excertos.

Genette (2009, p. 76) defende que "O título, como se sabe, é o "nome" do livro, e como tal, serve para nomeá-lo, isto é, designá-lo com tanta precisão quanto possível e sem riscos demasiados de confusão". Lispector apresenta um trabalho consistente neste sentido, pois manteve a opção do título nos trechos onde a expressão ocorre no original (conforme apresentado no Quadro 2):

Quadro 2 - Consistência no título do romance

\begin{tabular}{|lr|l|}
\hline $\begin{array}{lr}\text { Sou uma cabeça } \\
\text { decepada, tal como as }\end{array}$ & $\begin{array}{l}\text { I am a severed head such } \\
\text { as primitive tribes and old } \\
\text { das tribos primitivas e os }\end{array}$ \\
$\begin{array}{lrl}\text { alchemists used to use, } \\
\text { velhos }\end{array}$ & alquimistas & anointing it with oil and \\
\hline
\end{tabular}

\begin{tabular}{|c|c|}
\hline $\begin{array}{l}\text { costumavam usar, } \\
\text { lambuzando-as com óleo } \\
\text { e pondo um pedaço de } \\
\text { ouro sobre sua língua } \\
\text { para fazer, com ela, } \\
\text { perfeitas profecias. E, } \\
\text { quem sabe, se esta longa } \\
\text { familiaridader com } \\
\text { cabeças decepadas não } \\
\text { pode ter levado a um } \\
\text { estranho conhecimento? } \\
\text { (MURDOCH, 1974, p. } \\
\text { 155) } \\
\text { Em alguns segundos eu } \\
\text { estava em meio a um } \\
\text { sonho que tivera várias } \\
\text { vezes ultimamente. Um } \\
\text { sonho relacionado com } \\
\text { uma espada e uma } \\
\text { cabeça decepada } \\
\text { (MURDOCH, 1974, p. } \\
\text { 168). } \\
\text { Tentei não sorrir para ela. } \\
\text { - Você me disse que era } \\
\text { uma cabeça decepada. } \\
\text { Pode-se ter relações } \\
\text { humanas com uma } \\
\text { cabeça decepada? } \\
\text { (MURDOCH, 1974, p. } \\
\text { 175). }\end{array}$ & $\begin{array}{l}\text { putting a morsel of gold } \\
\text { upon its tongue to make it } \\
\text { utter prophecies. And who } \\
\text { knows but that long } \\
\text { acquaintance with a } \\
\text { severed head might not } \\
\text { lead to strange knowledge } \\
\text { (MURDOCH, 1961, p. } \\
\text { 182). } \\
\text { In a few seconds I was } \\
\text { adrift in a dream which I } \\
\text { had had several times } \\
\text { lately, a dream } \\
\text { concerning a sword and a } \\
\text { severed head } \\
\text { (MURDOCH, 1961, p. } \\
\text { 197). } \\
\text { I tried not to smile back. I } \\
\text { said, 'You told me you } \\
\text { were a severed head. Can } \\
\text { one have human relations } \\
\text { with a severed head?' } \\
\text { (MURDOCH, 1961, p. } \\
\text { 205). }\end{array}$ \\
\hline
\end{tabular}

No Quadro 2, no primeiro trecho, a tradutora utiliza uma estrutura diferente para comunicar sua ideia: em vez da versão literal, isto é, "um pedaço de ouro sobre sua língua para fazê-la proferir profecias", o que se tem é "pondo um pedaço de ouro sobre sua língua para fazer, com ela, perfeitas profecias". Evidencia-se, provavelmente, um caso de identificação errônea da classe gramatical de "utter" no trecho, tomado como adjetivo e significando "completo", "absoluto". Relendo o trecho, a opção mais viável seria considerar "utter", no caso, como verbo, o que evitaria todo o trabalho percebido no excerto, de tentar transformar a frase em algo inteligível. A escolha pela forma plural de "cabeça decepada" talvez cause estranhamento, pois justamente a fala é de Honor Klein, a personagem vista como tal, e que faz referência, em seguida, a ela mesma, e ao estranho conhecimento supostamente adquirido ao tê-la como conhecida há algum tempo (por parte de Martin, seu interlocutor no trecho). Ainda no Quadro 2, no segundo excerto, Lispector parece separar as sentenças com 
ponto final, enquanto Murdoch opta pelas vírgulas. Já no terceiro excerto, o verbo dicendi que aparece no original desaparece do texto traduzido, mas sem grandes prejuízos na narrativa - o que salva o trecho é o verbo em primeira pessoa da frase que antecipa a fala de Martin.

A polêmica questão sobre a tradução (ou não) de nomes próprios se faz presente neste romance: há quem defenda a prática (e talvez ela estivesse na moda na década de 1970), e há quem diga que os nomes, por carregarem diferentes conotações, não seriam passíveis de tradução para outros idiomas. Murdoch, segundo informações biográficas, pensava com muito carinho na criação de seus nomes, e raramente fazia uso de nomes da realidade: na verdade, o contrário costumava acontecer, pois as pessoas acabavam optando por adotar nomes (seja para filhos ou animais de estimação) que haviam sido lidos em algum de seus romances. Em $A$ Severed Head, observamos que os nomes Martin (narradorpersonagem), Antonia (esposa do narradorpersonagem), Rosemary (irmã do narradorpersonagem) e Honor (alvo do amor do narradorpersonagem) permaneceram conforme o original. Todavia, os demais nomes próprios foram traduzidos: Georgie transformou-se em Georgia (conforme visto no Quadro 1), e Alexander, Alexandre. Vejamos outro excerto, que coloca em pauta questões de interpretação:

Quadro 3 - Questão de interpretação

\begin{tabular}{|c|c|}
\hline $\begin{array}{l}\text { Saber o que vai acontecer } \\
\text { em maio que vem parece } \\
\text { um pouco improvável, } \\
\text { mas o leitor deverá me } \\
\text { acreditar que isto ocorreu. } \\
\text { Ela parou e voltou-se } \\
\text { novamente para encarar- } \\
\text { me. Pus o pé no primeiro } \\
\text { degrau e segurei-lhe o } \\
\text { braço rudemente } \\
\text { (MURDOCH, 1974, p. } \\
\text { 95). }\end{array}$ & $\begin{array}{l}\text { What happened next may } \\
\text { seem a little improbable, } \\
\text { but the reader must just } \\
\text { believe me that it did } \\
\text { occur. She paused and } \\
\text { turned round again to face } \\
\text { me. I set my foot on the } \\
\text { lowest step and seized } \\
\text { her arm roughly } \\
\text { (MURDOCH, 1961, p. } \\
\text { 147). }\end{array}$ \\
\hline
\end{tabular}

Após a leitura cotejada, fica visível a confusão com "may" que, na sintaxe apresentada no texto original, funciona como verbo modal, e não como substantivo (isto é, a referência ali não é ao mês de maio, como foi a opção escolhida na tradução). $\mathrm{Na}$ história, e nesta parte em específico, não há menção a meses do ano, portanto, isso não justificaria a escolha dessa opção de tradução. Além disso, a frase toda precisou de ajustes para comportar essa interpretação que, a nosso ver, soa equivocada: em vez de optar pelo literal (isto é, "o que aconteceu depois poderia parecer um pouco improvável"), foi necessário incluir o infinitivo "saber" para, aí sim, dar continuidade à sentença.

Quando à intertextualidade, definida por Genette (2010, p. 14) como "uma relação de copresença entre dois ou vários textos, isto é, essencialmente, e o mais frequentemente, como presença efetiva de um texto em um outro", no caso de Iris Murdoch, que transita muito entre filosofia e literatura, as referências são um tanto abundantes, embora possam ficar imperceptíveis para um leitor comum ou menos atento (isto é, que não tenha expertise em filosofia ou em literatura para detectar possibilidades de alusões). Nesta tradução, trechos de intertextualidade explícita, isto é, estrofes de poemas e citações em inglês, permaneceram conforme o original, sem notas que pudessem sinalizar ao leitor sua origem ou sua pertinência. O capítulo 6 , por exemplo, já no seu início, contém os seguintes versos, apresentados no Quadro 4:

Quadro 4 - Tratamento da intertextualidade Robert Service

\begin{tabular}{|c|c|}
\hline $\begin{array}{l}\text { "Desde que deixei } \\
\text { Plumtree } \\
\text { Lá no Tennessee } \\
\text { É a primeira vez que me } \\
\text { sinto aquecido!" } \\
\text { Cantarolou Alexandre, } \\
\text { enquanto movimentava } \\
\text { suas longas mãos de } \\
\text { unhas largas em frente } \\
\text { do novo aquecedor } \\
\text { elétrico. A manga do seu } \\
\text { avental branco dobrava- } \\
\text { se e inflava-se com o } \\
\text { vento quente }\end{array}$ & $\begin{array}{l}\text { 'Since I left Plumtree } \\
\text { Down in Tennessee } \\
\text { It's the first time l've been } \\
\text { warm!' } \\
\text { quoted Alexander, as he } \\
\text { dangled his long broad- } \\
\text { nailed hand in front of his } \\
\text { new fan heater. The } \\
\text { sleeve of his white smock } \\
\text { fluttered and rippled in } \\
\text { the warm wind } \\
\text { (MURDOCH, 1961, p. } \\
\text { 39). }\end{array}$ \\
\hline
\end{tabular}


(MURDOCH, 1974, p.

33).

Os versos citados aparecem no poema "The Cremation of Sam McGee", do poeta inglês Robert W. Service (1874-1958), publicado em 1907. A referência no trecho é à temperatura, já que o poema narra a cremação de um prospector que morre de frio próximo ao Lago Laberge, em Yukon, no Canadá. Talvez uma nota de rodapé explicando brevemente essa referência não parecesse necessária para alguns, mas certamente deixaria o texto de Murdoch mais inteligível, justamente pela apta comparação (ou melhor, alusão) por meio dos versos declamados pelo personagem, destacando, inclusive, sua personalidade e conhecimento. No entanto, uma ressalva precisa ser feita: estamos lendo uma tradução produzida na década de 1970, quando os recursos eram escassos (as informações não estavam disponíveis da forma que conhecemos hoje). Assim, temos a sensação de que pode até ter havido uma pesquisa por parte da tradutora, ou de seus revisores, e que talvez esse esforço tenha sido infrutífero. De fato, o exercício de análises de tradução no século XXI precisa do esforço de voltarmos ao passado e pensarmos que não existiam computadores sofisticados equipados com memórias de tradução, amplos dicionários e outras tantas ferramentas. $O$ próximo trecho traz outra referência intertextual:

Quadro 5 - Tratamento intertextualidade -

William Shakespeare

\begin{tabular}{|l|l|}
\hline "The ousel-cock, so black & $\begin{array}{l}\text { "The ousel-cock, so black } \\
\text { of hue, }\end{array}$ \\
With Orange-tawny bill," & With Orange-tawny bill," \\
Alexandre murmurou: & Alexander murmured. \\
- Você recita bem, irmão. & 'You quote too aptly, \\
- Bem demais? & brother.' \\
- Não se lembra do resto? & 'Too aptly?' \\
- Não. & 'You don't recall the rest?' \\
"The throstle with his note & 'No.' \\
so true, & "The throstle with his note \\
The wren with little quill, & so true, \\
The finch, the sparrow, & The wren with little quill, \\
and the lark, & The finch, the sparrow, \\
The plain-song cuckoo & and the lark, \\
gray, & The plain-song cuckoo \\
Whose note full many a & gray, \\
man doth mark, & Whose note full many a \\
And dare not answer nay." & man doth mark, \\
(MURDOCH, 1974, p. & And dare not answer nay." \\
39). & (MURDOCH, 1961, p. \\
\hline
\end{tabular}

Depois de uma breve pesquisa, constatamos ser um trecho da peça de William Shakespeare Sonho de uma noite de verão (mais precisamente, Ato 3, cena 1). Novamente, as considerações anteriores permanecem válidas: apenas um leitor extremamente atento, ou exímio conhecedor da obra de Shakespeare (que provavelmente possua trechos memorizados), conseguiria detectar a referência sem uma consulta às cegas. Lembrando que o trabalho de tradução, pelo menos na época considerada, era extremamente precário em termos de acesso a referências.

Outro item que chamou a atenção quanto às características estilísticas do texto da tradução foi a opção pela literalidade da tradução dos tempos verbais do inglês. Vejamos o efeito dessas escolhas no trecho exibido no Quadro 6:

Quadro 6 - Literalidade na tradução dos tempos verbais

\begin{tabular}{|c|c|}
\hline e & $\begin{array}{l}\text { 'Antonia has been te } \\
\text { me about your flat,' } \\
\text { Rosemary. 'It sou } \\
\text { ideal. And there's } \\
\text { heavenly view ove } \\
\text { Westminster Cathedr } \\
\text { 'Well, you know } \\
\text { about it than I do,' I } \\
\text { Palmer had found } n \\
\text { flat in Lowndes Squa } \\
\text { appeared to be all rig } \\
\text { 'But you wouldn't let } \\
\text { tell you this morn } \\
\text { exclaimed Antonia. } \\
\text { he dreadful?' } \\
\text { Rosemary. 'Don't } \\
\text { even want to see it?' } \\
\text { 'Not specially.' } \\
\text { 'Dear heart, don't s } \\
\text { said Antonia. 'You'll } \\
\text { to make some dec } \\
\text { soon about the furni } \\
\text { Rosemary and I have } \\
\text { been measuring curt } \\
\text { and the landing and } \\
\text { Room ones will fit ex } \\
\text { without altera } \\
\text { (MURDoch, 1961, } \\
\text { A8) }\end{array}$ \\
\hline
\end{tabular}

Conforme exposto no Quadro 6, destacamos que a tradução literal no português brasileiro dos tempos verbais contínuos do inglês ("tem estado falando", "temos estado medindo") inevitavelmente torna a leitura cansativa. Por mais que haja o trabalho de pensar em vocábulos adequados para a tradução de outros trechos, os tempos verbais representam uma 
parte importante do andamento de qualquer narrativa, ainda mais quando temos um narrador em primeira pessoa que participa das ações, como é o caso em $A$ Cabeça Decepada.

Uma possível falha de revisão (pois ela ocorre apenas nesse trecho em destaque) diz respeito ao elemento de cor local - uma vez que a história se passa em Londres - e Oxford e Cambridge - e referências reais ao local são frequentes e demandam atenção por parte do tradutor, já que se tornam uma característica da escrita de Iris Murdoch:

Quadro 7 - Elementos da cor local

\begin{tabular}{|c|c|}
\hline - Cinco e cin & fifty-seven \\
\hline Liverpool & Liverpool \\
\hline você é um & Antonia. 'Martin, you're an \\
\hline Receio que o trem esteja, & ace. I'm afraid the train's \\
\hline $\begin{array}{l}\text { por certo, com terrível } \\
\text { atraso por causa do }\end{array}$ & $\begin{array}{l}\text { sure to be awfully late } \\
\text { because of the fog. }\end{array}$ \\
\hline nevoeiro. Talvez você & Perhaps you could bring \\
\hline possa trazê-la diretamente & her straight to Pelham \\
\hline $\begin{array}{l}\text { à Pelham Crescent. } \\
\text { Imagino se você tem a }\end{array}$ & $\begin{array}{l}\text { Crescent. I wonder if you } \\
\text { have the faintest idea how }\end{array}$ \\
\hline $\begin{array}{l}\text { mais fraca idéia do quanto } \\
\text { você é bom (MURDOCH, }\end{array}$ & $\begin{array}{l}\text { good you are? } \\
\text { (MURDOCH, 1961, p. 52). }\end{array}$ \\
\hline $\begin{array}{l}\text { A estação da rua de } \\
\text { Liverpool cheirava a } \\
\text { enxofre. Um nevoeiro fino } \\
\text { a cobria e a grande cúpula } \\
\text { de ferro fundido estava } \\
\text { invisível (MURDOCH, } \\
\text { 1974 p. 45). }\end{array}$ & $\begin{array}{l}\text { Liverpool Street Station } \\
\text { smelt of sulphur and } \\
\text { brimstone. Thick fog filled } \\
\text { it and the great cast-iron } \\
\text { dome was invisible } \\
\text { (MURDOCH, 1961, p. 53). }\end{array}$ \\
\hline
\end{tabular}

Conforme demonstrado no Quadro 7, "A estação da rua de Liverpool" causa estranhamento no contexto, justamente porque, para um leitor desavisado, ele pode pensar que a narrativa talvez tenha mudado repentinamente de Londres para Liverpool, o que não acontece. Acredita-se que possa ter havido algum lapso no momento da revisão do fragmento - embora não estejamos atribuindo a tarefa necessariamente apenas ao nome que consta na edição, que é o de Naasson Vieira Peixoto. Outro aspecto no final do segundo trecho no Quadro 8 é a sinonímia no inglês entre "sulphur" e "brimstone" que pode, em um primeiro momento, atrapalhar um pouco o leitor deste artigo, após fazer o cotejamento entre os dois trechos. Na tradução vemos a opção pela forma genérica em português (e que, a nosso ver, não causa penalidades na tradução), que consegue responder pelos dois vocábulos no original: enxofre. Alguns poderiam reclamar de um "empobrecimento quantitativo" (seguindo a terminologia de Antoine Berman): isto é, haveria um "desperdício lexical [...] pois tem-se menos significantes na tradução do que no original" (BERMAN, 2012, p. 76). Até poderíamos pensar em uma solução forçada e incluir "súlfur", que seria uma opção para "brimstone" (que tem um sentido mais bíblico no inglês). Atentamos também para a tradução de "fog": nos trechos selecionados, a opção foi por "nevoeiro". No entanto, em outros excertos encontramos a palavra em inglês, como exposto no Quadro 8:

Quadro 8 - A tradução de fog

\begin{tabular}{|l|l|}
\hline $\begin{array}{l}\text { Segurando a cabeça que já } \\
\text { estava para estourar, }\end{array}$ & $\begin{array}{l}\text { Then, holding my head, } \\
\text { which felt ready to break } \\
\text { levantei-me trêmulo. Subi } \\
\text { open, I got shakily to my } \\
\text { as escadas com dificuldade } \\
\text { feet. I got myself up the } \\
\text { e fui para a entrada. A porta } \\
\text { da frente estava aberta. Lá } \\
\text { fora, pendurado como uma } \\
\text { the front door was open } \\
\text { coberta, há um metro da } \\
\text { antrada, outside, hung like a } \\
\text { blanket a yard from the } \\
\text { amarelo, sombrio, infernal, } \\
\text { completamente imóvel. } \\
\text { opening, was the fog, } \\
\text { yellow, opaque, infernal, } \\
\text { completely still. I stood in } \\
\text { thei em pé na porta } \\
\text { (MURDOCH, 1974, p. 96). }\end{array}$ \\
$\begin{array}{l}\text { (MURDOCH, 1961, p. } \\
112) .\end{array}$
\end{tabular}

Talvez a opção durante a revisão do texto tenha sido pela forma em português, e durante o processo, algumas ocorrências inevitavelmente permaneceram sem alteração. Outra consideração talvez foi manter os trechos no original e deixar que o leitor mesmo as identificasse. Outro aspecto importante deste trecho é o desvio da norma culta quando aparece o verbo "há", em vez de "a", para a expressão "a um metro da entrada". A ênclise ocorre novamente ("levantei-me").

Outro tópico relacionado ao processo editorial desenvolvido nos anos 1970 diz respeito à presença de saltos de tradução, isto é, a trechos que não foram traduzidos (daí a terminologia utilizada). Na tradução para o português, o leitor fica sem acesso a, pelo menos, um parágrafo da história, conforme demonstrado no Quadro 9: 
Quadro 9 - Salto de tradução (um parágrafo)

Eu estava longe de
confiar nisso. Entretanto,
em meus devaneios, eu
timidamente trazia à
memória a imagem de
minha amante. Rosemary
devia encontrar-me
comigo em Oxford e
conduzir-me de
automóvel a Rembers
(MURDOCH, 1974, p.
30).
$30)$.
I was far from sure of this, however, and my thoughts warily, even shyly, returning inconclusively to the image of my mistress. I had not communicated with Georgie since that day of the revelation, and since the thing was not yet common knowledge, she was still presumably ignorant of the change in my situation. I did not look forward to telling her. It was not a time at which I felt well able to have things expected of me; and as I speculated and wondered about what exactly Georgie would expect, it occurred to me how little, after all, I knew her. That she would vulgarly press me to marry her was of course out of the question. It was a matter rather of how far and how she would, in turn, let me off; it was an additional, and when I attended to it a terrible, pain that if in this new situation either Georgie or I 'flagged' we would be betraying and indeed destroying a precious and tender relation which in secrecy and ambiguity had so much flourished. I needed Georgie, I loved her, I felt I could not possibly, especially now, do without her. Yet I did not quite see myself marrying her. Still, it was, I reflected, far too soon to know. I had not yet even begun to fit the pieces together; and there might be some way of fitting them together which would make out a picture of happiness for me and for Georgie. At rare moments, in a quite abstract way, I imagined this happiness, something

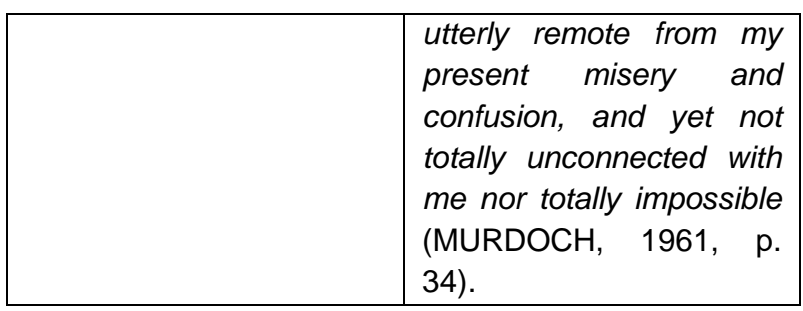

Constatamos isso porque paramos para fazer essa leitura cotejada e atenta - o leitor que adquire o livro e lê a história apenas na tradução provavelmente não sentirá falta do excerto. No entanto, entendemos que os saltos podem ocorrer em qualquer processo editorial (como de fato ainda são verificados em inúmeras publicações, apesar de todos os avanços tecnológicos desenvolvidos nos últimos anos) e que, no passado, embora houvesse atenção, os meios de trabalho talvez não fossem os mais adequados para evitar que isso acontecesse com frequência. $O$ que sugerimos, neste artigo, é pensar em uma possibilidade de reedição do romance, com a inclusão dos saltos identificados (alguns mais consideráveis, como o apresentado no Quadro 9, outros mais curtos, como o mostrado no Quadro 10):

Quadro 10 - Salto de tradução (falha visual)

\begin{tabular}{|c|c|}
\hline $\begin{array}{l}\text { - Na verdade, antes do } \\
\text { nosso casamento. } \\
\text { Somente que eu não } \\
\text { acreditava no meu amor } \\
\text { até que foi tarde demais. } \\
\text { Você lembra que você não } \\
\text { me deixava encontrar } \\
\text { Alexandre até que o nosso } \\
\text { noivado foi anunciado? } \\
\text { (MURDOCH, 1974, p. } \\
\text { 160) }\end{array}$ & $\begin{array}{l}\text { 'Really since before we got } \\
\text { married. I fell in love with } \\
\text { Alexander practically as } \\
\text { soon as I met him. Only I } \\
\text { didn't start to believe in my } \\
\text { love until it was too late. } \\
\text { You remember you } \\
\text { wouldn't let me meet } \\
\text { Alexander until after our } \\
\text { engagement was } \\
\text { announced. You said he } \\
\text { always } \\
\text { took your girls away. And } \\
\text { then everything was so } \\
\text { public. I hadn't enough } \\
\text { nerve' (MURDOCH, 1961, } \\
\text { p. 188). }\end{array}$ \\
\hline
\end{tabular}

Por mais insignificantes que pareçam, esses pequenos trechos compõem a história, esmiuçando as reações das personagens. Percebemos que os saltos ocorrem às vezes muito mais pela falha visual na leitura (isto é, pelo pulo mesmo da visão) do que propriamente pela dificuldade de sua tradução (o que explicaria alguns saltos identificados em algumas edições, quando o tradutor acha algum trecho de difícil 
tradução e opta por ignorá-lo e/ou eliminá-lo). Outro salto é apresentado no Quadro 11:

Quadro 11 - Salto de tradução (falha visual)

-Querido, eu sabia que você aceitaria! Ela veio por trás de mim e eu podia sentir sua terna aflição. Começou a tomar minhas mãos e envolvê-las com as dela. Sem me voltar, eu deixei que as tomasse

(MURDOCH, 1974, p. 161).
'Dearest,' said Antonia, 'I knew you'd come round!' She came up behind me and I could feel her gentle touch on my shoulder. I still stood looking out at the magnolia, my hands behind my back.

'What makes you think I'm coming round?' I said. 'You must, you must!' she said with tender urgency, and began to undo my hands and take them in hers. Without turning I let her hold them (MURDOCH, 1961, p. 189).

Novamente, parece haver uma espécie de corte no texto, pois o que nos guia na leitura cotejada é a expressão "terna aflição", que aparece mais ao final no trecho original como "tender urgency", mas as sentenças que preenchem esse espaço desapareceram, isto é, foram puladas na tradução. Mais uma vez, há a possibilidade real de que tenha sido um lapso visual.

\section{Considerações Finais}

"Bons escritores não são necessariamente bons tradutores" parece uma máxima imediatamente tentadora quando nos debruçamos sobre o texto da tradução, atribuída a Clarice Lispector, de A Cabeça Decepada. Todavia, chama-se a atenção para o fato de este artigo ter como principal objetivo apresentar um primeiro esforço de possível aproximação e análise desses dois grandes nomes nas literaturas brasileira e inglesa por meio da tradução - obviamente, estamos admitidamente trabalhando com a hipótese de que Clarice Lispector tenha realmente atuado neste projeto de tradução como tradutora. A partir desta pesquisa, pretende-se impulsionar e estimular re(leituras) comparatistas não apenas deste romance, mas dos demais produzidos por Iris Murdoch e disponíveis em português brasileiro.

Quanto ao resultado final de nossa análise da edição brasileira de $A$ Cabeça Decepada, podemos afirmar que se trata de um texto, inevitavelmente, datado (por ter sido produzido há mais de 45 anos) e que possui, sim, alguns equívocos de interpretação que permaneceram na versão final enviada à prensa, o que, todavia, não tira os méritos do texto, considerando os recursos de editoração e mesmo de tradução disponíveis na época. Outro ponto é que seriam poucos os leitores brasileiros que realizariam essa leitura cotejada entre original e tradução, logo, ao longo de todos esses anos, muito pouco (ou possivelmente nada) foi mencionado em relação, especificamente, à tradução do romance de Iris Murdoch A Cabeça Decepada, e nosso artigo pretende também ser um registro da recepção da obra no Brasil, embora isso esteja sendo feito quando já estamos no século XXI.

Novamente, a expressão "tradução atribuída a Clarice Lispector" se explica porque, mesmo a partir da análise apresentada aqui de forma um tanto resumida - afinal, apesar de poucos, os excertos selecionados conseguiram demonstrar as escolhas lexicais realizadas, a literalidade observada em certas estruturas, alguns trechos com interpretações equivocadas e a ocorrência de saltos importantes -, não é possível afirmar categoricamente que Lispector não tenha participado como tradutora deste projeto, nem que ela tenha realmente participado. Logo, a nossa sugestão, a partir da iniciativa descrita neste artigo, é que pesquisadores, no futuro próximo, se interessem por uma possível reedição da tradução do romance, para dar conta da datação e também dos equívocos identificados, visando a aperfeiçoar a qualidade do material disponibilizado ao público leitor brasileiro, independentemente da conexão (ou não) de Clarice Lispector neste projeto de tradução (afinal, a dúvida sobre sua autoria ainda paira no ar). Talvez seja justamente o benefício da dúvida que ainda fascine e estimule os pesquisadores a se debruçarem sobre estes materiais. 


\section{REFERÊNCIAS}

BERMAN, Antoine. A tradução e a letra ou o albergue do longínquo. 2. ed. Traduzido por Marie-Hélène $C$. Torres, Mauri Furlan e Andreia Guerini. Florianópolis: PGET/UFSC, 2013, $198 p$

\section{BIBLIOTECA NACIONAL DE PORTUGAL. Iris Murdoch.} Disponível em:

<http://bibliografia.bnportugal.gov.pt/bnp/bnp.exe/q?mfn=21 4638\& qf $A U==M U R D O C H \% 2 C \% 20 I R I S \% 2 C \% 201919$ 1999>. Acesso em: 30 abr. 2021.

CORACINI, Maria J. The (well)-(ill) being of the translator between languages-cultures. Conexão Letras: revista do Programa de Pós Graduação em Letras da UFRGS, Porto Alegre, v. 12, n. 17, p. 11-21, Disponível em:

$<$ https://seer.ufrgs.br/conexaoletras/article/view/75596/4287 0>. Acesso em: 30 abr. 2021.

EDITORA ARTENOVA. Disponível em:

<https://pt.wikipedia.org/wiki/Artenova> Acesso em: 30 abr. 2021.

ENGLISH, James F. British fiction in a global frame. In: A concise companion to contemporary British fiction. 1. ed. Reino Unido: Blackwell Publishing, 2006. p. 1-15.

FERREIRA, Rony Márcio C. Clarice Lispector: uma tradutora em fios de seda (teoria, crítica e tradução literária). Orientador: Germana Henriques Pereira de Sousa. 2016. $366 \mathrm{f}$. Tese (Doutorado em Letras - Literatura) - Instituto de Letras (IL) - Universidade de Brasília, Brasília, DF, 2016, 366 p. Disponível em:

<https://repositorio.unb.br/handle/10482/23169>. Acesso em: 30 abr. 2021.

PEREIRA, Germana H. Crônica de uma tradutora anunciada: Clarice e a tradução como dever. Revista da Anpoll, Florianópolis, v. 1, n. 47, p. 76-92, set-dez, 2018, 16 p. Disponível em: <

https://revistadaanpoll.emnuvens.com.br/revista/article/view/ 1199>. Acesso em: 30 abr. 2021.

GOMES, André L. Entre espelhos e interferências: a problemática da tradução para Clarice Lispector. Via Atlântica, São Paulo, v. 1, n. 7. p. 39-52, dez, 2004, 13 p. Disponível em:

' A Iris Murdoch Centenary Conference foi realizada em Oxford, em julho de 2019, e na ocasião apresentamos os desafios encontrados na tradução da novela Something Special para o português brasileiro.

" No original em inglês: "[...] tending to mean the Movement, the Angry Young Men, the first generation of feminist novels [...]." (ENGLISH, 2006, p. 2).

'II A Iris Murdoch Centenary Conference foi realizada em Oxford, em julho de 2019, e na ocasião apresentamos os desafios encontrados na tradução da novela Something Special para o português brasileiro.

"No original em inglês: "[...] tending to mean the Movement, the Angry Young Men, the first generation of feminist novels [...]." (ENGLISH, 2006, p. 2).

$\checkmark$ No original em inglês: "a novel that explores sadomasochism, violence and incest, and in dealing with such sensitive issues, relies on imagery, poetics and symbols to portray meaning. [...] The novel suggests that deep inexplicable Freudian impulses impact on human behaviour more palpably than societal law, and that a deep irrationality hides beneath a fragile veneer of civilization (ROWE, 2019, p. 16). (ROWE, 2019, p. 16, tradução nossa).
$<$ https://www.revistas.usp.br/viaatlantica/article/view/49784> . Acesso em: 30 abr. 2021

GENETTE, Gérard. Palimpsestos: a literatura de segunda mão. Traduzido por Cibele Braga, Erika Viviane Costa Vieira, Luciene Guimarães, Maria Antônia Ramos Coutinho, Mariana Mendes Arruda, Miriam Vieira. 1. ed. Belo Horizonte: Edições Viva Voz, 2010, 168 p.

Paratextos editoriais. Traduzido por Álvaro Faleiros. 1. ed. São Paulo: Ateliê Editorial, 2009, 372 p.

GOTLIB, Nádia B. Clarice: uma vida que se conta. 6. ed. São Paulo: Edusp, 2009, 656 p.

HANES, Vanessa L. L.; GUERINI, Andréia. Clarice Lispector traduzida e tradutora: estado da arte. Revista da Anpoll, Florianópolis, v. 1, n. 41, p. 172-183, jul-dez, 2016, 11 p. Disponível em: <

https://revistadaanpoll.emnuvens.com.br/revista/article/view/ 942>. Acesso em: 30 abr. 2021.

MURDOCH, Iris. A cabeça decepada. Traduzido por Clarice Lispector. Rio de Janeiro: Artenova, 1974

MURDOCH, Iris. A severed head. 1. ed. Londres: Penguin 1961.

NOLASCO, Edgar C. Clarice Lispector tradutora. Revista Cerrados: revista do Programa de Pós-Graduação em Literatura da UNB, Brasília, v. 16, n. 24, p. 263-272, nov., 2007, 10 p. Disponível: <

https://periodicos.unb.br/index.php/cerrados/article/view/261 15>. Acesso em: 30 abr. 2021.

ROWE, Anne. Iris Murdoch. 1. ed. Liverpool: Liverpool University Press, 2019, 160 p.

STEFANI, Mônica; PEREIRA, Tiago Ferreira. Iris Murdoch e Clarice Lispector: A tradução do romance a cabeça decepada. Signo, Santa Cruz do Sul, v. 46, n. 87, sep. 2021. ISSN 1982-2014. Disponível em: $<$ https://online.unisc.br/seer/index.php/signo/article/view/ 16531>. doi:https://doi.org/10.17058/signo.v46i87.16531.

VI Em Portugal, até o momento, foram traduzidos 10 dos 26 romances de Iris Murdoch, conforme pesquisa realizada no site da Biblioteca Nacional de Portugal, disponível em: $<$ http//bibliografia bnportugal gov.pt/bnp/bnp exe/q?mfn=21463 8\&qf_AU==MURDOCH\%2C\%20IRIS\%2C\%201919-1999> Acesso em: 24 fev. 2021.

VII Por exemplo, a tese de Rony M. Cardoso Ferreira (2016), intitulada Clarice Lispector: Uma Tradutora em Fios de Seda (Teoria, Crítica e Tradução Literária) ajuda os pesquisadores na busca de referências tradutórias. Outros trabalhos se detêm na materialidade do texto das traduções de Clarice Lispector, como o artigo de Rony Ferreira e Germana Pereira, intitulado Crônica de uma Tradutora Anunciada: Clarice e a Tradução como Dever, de 2018, analisa o trabalho de Clarice Lispector em um conto francês.

VIII A moça italiana (1974) e O unicórnio (1975) pela editora Artenova; e O mar, O mar (1980) pela editora Nova Fronteira.

ıx Na página 326 da tese de Ferreira (2016). 